\title{
Automation in indirect immunofluorescence testing: a new step in the evolution of the autoimmunology laboratory
}

\author{
Renato Tozzoli • Antonio Antico • Brunetta Porcelli • \\ Danila Bassetti
}

Received: 9 June 2012/Accepted: 19 June 2012/Published online: 13 July 2012

(C) Springer-Verlag 2012

\begin{abstract}
Indirect immunofluorescence (IIF) plays an important role in immunological and immunometric assays for detecting and measuring autoantibodies. This technology was the first multiplex method used to detect cardinal autoantibodies for the diagnosis of autoimmune diseases. Over the last 20 years, research has enabled the progressive identification of cell and tissue autoantigens which are the target of autoantibodies originally detected by IIF. Accordingly, newer immunometric methods, capable of measuring concentrations of specific autoantibodies directed against these autoantigens, allowed for a gradual replacement of the IIF method in the autoimmunology laboratory. Currently, IIF remains the method of choice only in selected fields of autoimmune diagnostics. Following the recent statement by the American College of Rheumatology that the IIF technique should be considered as the standard screening method for the detection of ANA, the biomedical industry has developed technological solutions which significantly improve automation of the procedure, not only in the preparation of substrates and slides,
\end{abstract}

R. Tozzoli $(\bowtie)$

Laboratory of Clinical Pathology,

Department of Laboratory Medicine, S. Maria degli Angeli

Hospital, Via Montereale, 24, 33170 Pordenone, Italy

e-mail: tozzoli@libero.it; renato.tozzoli@aopn.fvg.it

\author{
A. Antico \\ Laboratory of Clinical Pathology, City Hospital, Cittadella, Italy \\ B. Porcelli \\ Laboratory of Clinical Pathology, Department of Internal \\ Medicine, University Hospital, Siena, Italy \\ D. Bassetti \\ Laboratory of Microbiology and Virology, \\ S. Chiara Hospital, Trento, Italy
}

but also in microscope reading. This review summarizes the general and specific features of new available commercial systems (Aklides, Medipan; Nova View, Inova; Zenit G Sight, A. Menarini Diagnostics; Europattern, Euroimmun; Helios, Aesku.Diagnostics; Image Navigator, Immuno Concepts; Cytospot, Autoimmun Diagnostika) for automation of the IIF method. The expected advantages of automated IIF are the reduction in frequency of false negative and false positive results, the reduction of intraand inter-laboratory variability, the improvement of correlation of staining patterns with corresponding autoantibody reactivities, and higher throughput in the laboratory workflow.

Keywords Autoimmune diseases · Indirect immunofluorescence · Automation · Standardization

\section{Introduction}

Indirect immunofluorescence (IIF), a general method for detecting and measuring antibodies and autoantibodies, plays an important role within the immunological and immunometric assays (IMA) (reviewed in [1]). This technology was the first multiplex method used to detect cardinal autoantibodies for the diagnosis of autoimmune diseases (AIDs), beginning with antinuclear antibodies (ANA) in 1957 to endomysium antibodies in 1984 (Table 1) [2-15]. In some applications however, (i.e., for ANA, anti-thyroid antibodies, etc.) IIF is actually a multiplex method, given that it is able to detect from 2 to more than 60 autoantibodies simultaneously; in the case of ANA, it allows the identification of at least 26 different cellular patterns [16]. Thanks to the use of various animal and human tissues (liver, kidney, stomach, esophagus, 
Table 1 Milestones of indirect immunofluorescence in the history of autoantibody testing

\begin{tabular}{ll}
\hline Autoantibody & Author \\
\hline Antinuclear & Friou [2] \\
Anti-thyroglobulin & Nairn [3] \\
Anti-parietal cells & Taylor [4] \\
Anti-intercellular substance & Beutner [5] \\
Anti-mitochondria & Walker [6] \\
Anti-smooth muscle & Johnson [7] \\
Anti-adrenal cortex & Irvine [8] \\
Anti-steroid cells & Anderson [9] \\
Anti-reticulin & Seah [10] \\
Anti-liver-kidney microsomes & Rizzetto [11] \\
Anti-islet cells & Bottazzo [12] \\
Anti-pituitary cells & Bottazzo [13] \\
Anti-gliadin & Unsworth [14] \\
Anti-endomysium & Chorzelski [15] \\
\hline
\end{tabular}

pituitary, pancreas, bladder, nerve tissue, etc.) and isolated cells (human laryngeal HEp-2 carcinoma cells, Crithidia luciliae hemoflagellates, human neutrophil granulocytes, fibroblasts, intestinal cells, VSM 47 cells, HEK-239 cells, etc.), IIF has permitted the detection of an extensive series of specific autoantibodies directed against cellular autoantigens. This method, in time, became a consolidated and universally diffused procedure for detecting patients affected by AIDs, with differentiated use in the different pathologies, according to analytical sensitivity and specificity of the different types of substrates.

\section{The current role of indirect immunofluorescence}

Since the turn of the millennium, there has been a rapid advance in diagnostic technology for detection and quantitation of autoantibodies [17]. The reasons for this technological revolution are (a) the increment of awareness of the physiopathogenetic and diagnostic role of autoantibodies in systemic and organ-specific autoimmune diseases; (b) the refinement of procedures for identifying and purifying the target autoantigens of the autoimmune reaction; (c) the application of quantitative immunological methods to automated analytic systems and platforms; and (d) the development of proteomic multiplex technologies, able to detect simultaneously a high number of autoantibodies in the same sample.

Over the last 20 years, basic research has enabled the progressive identification of cell and tissue autoantigens which are the target of autoantibodies originally detected by IIF. Accordingly, immunometric methods capable of measuring concentrations of specific autoantibodies directed against these autoantigens have been introduced, with a
Table 2 Current use of immunological methods for the detection of autoantibodies in clinical laboratories

\begin{tabular}{lll}
\hline Autoantibody & IIF & IMA \\
\hline ANA & +++ & + \\
Anti-dsDNA & +++ & +++ \\
Anti-ENA & - & +++ \\
AMA & +++ & +++ \\
PCA & +++ & ++ \\
ASMA & +++ & ++ \\
ACA & +++ & $-1+$ \\
APA & ++ & - \\
ATA & - & +++ \\
EmA & ++ & +++ \\
ICA & + & +++ \\
ASA & +++ & + \\
ASCA & + & +++ \\
ANCA & +++ & ++ \\
\hline
\end{tabular}

$I I F$ indirect immunofluorescence, IMA immunometric assays, ANA antinuclear antibodies, ENA extractable nuclear antibodies, $A M A$ antimitochondrial antibodies, $P C A$ parietal cells antibodies, $A C A$ adrenal cortex antibodies, $A P A$ anti-pituitary antibodies, $A T A$ anti-thyroid antibodies, EmA anti-endomysial antibodies, ICA islet cells antibodies, ASA anti-skin antibodies, ASCA anti-Saccharomyces cerevisiae antibodies, ANCA anti-neutrophil cytoplasmic antibodies

progressive replacement of the IIF method in the autoimmunology laboratory [18]. Currently, IIF remains the method of choice in selected fields of autoimmune diagnostics and its relationship with other IMA methods is indicated in Table 2.

The IIF method is now considered the reference method for ANA and anti-neutrophil cytoplasmic antibody (ANCA) screening and a confirmatory test for anti-dsDNA antibody detection [19-22]; other common uses relate to the detection of anti-mitochondria, anti-smooth muscle, anti-adrenal cortex, anti-pituitary, and anti-skin autoantibodies.

However, the method is burdened by some unfavorable features: the need for expert morphologists, the subjectivity of interpretation, and the low degree of standardization and automation [23, 24]. Because of these limitations and the progressive increase of autoantibody test requests in autoimmunology laboratories, particularly in the case of ANA, over the last 15 years innovation in the technology of analytical platforms has offered the availability of alternative solutions to the IIF method, based on the manual or automated monoplex IMA (mainly of the ELISA type), with the use of solid phases coated by a mixture of nuclear-cytoplasmic antigens. The literature reports have demonstrated that these manual [25-36] or automated [37-40] systems do not provide the same analytic accuracy as IIF, in particular for the presence of false negative results (up to $35 \%$ of cases) in case of rare autoantibodies. Therefore, it is maintained that the IMA monoplex methods 
Table 3 General features of automated IIF commercial platforms

\begin{tabular}{|c|c|c|c|}
\hline System & Company & $\begin{array}{l}\text { Neg/pos } \\
\text { automated } \\
\text { screening }\end{array}$ & $\begin{array}{l}\text { Automated pattern } \\
\text { recognition no. (type) }\end{array}$ \\
\hline Aklides & Medipan, DE & Yes & $\begin{array}{l}7 \text { (homogeneous, speckled, nucleolar, } \\
\text { centromeric, nuclear dots, mitotic, } \\
\text { cytoplasmic) }\end{array}$ \\
\hline Europattern & Euroimmun, DE & Yes & $\begin{array}{l}8 \text { (homogeneous, speckled, nucleolar, } \\
\text { centromeric, nuclear dots, mitotic, } \\
\text { nuclear membrane, cytoplasmic) }\end{array}$ \\
\hline $\begin{array}{l}\text { Zenit } \\
\text { G-Sight }\end{array}$ & Menarini, IT & Yes & $\begin{array}{l}5 \text { (homogeneous, speckled, nucleolar, } \\
\text { centromeric, cytoplasmic/mitochondrial) }\end{array}$ \\
\hline Nova View & Inova, USA & Yes & $\begin{array}{l}5 \text { (homogeneous, speckled, nucleolar, } \\
\text { centromeric, nuclear dots) }\end{array}$ \\
\hline Helios & Aesku, DE & Yes & None \\
\hline $\begin{array}{l}\text { Image } \\
\text { Navigator }\end{array}$ & Immunoconcepts, USA & Yes & None \\
\hline CytoSpot & Autoimmun Diagnostika, DE & Yes & None \\
\hline
\end{tabular}

do not represent a substitute for IIF, not even in unusual analytic conditions or when faced with a high volume of test requests.

The introduction of multiplex methods, able to simultaneously measure several ANA-related antibodies, gave rise to the hypothesis that they can be used as a screening platform for ANA testing as an alternative to IIF. However, the sensitivity of the ANA screening test with multiplex immunoassay is not yet adequate and the presence of false negative results is similar to the previously discussed monoplex IMA methods [1, 41-44], varying from 0.2 to $40.5 \%$ depending on the population studied.

\section{Automation in indirect immunofluorescence}

Following the recent statement made by the American College of Rheumatology that the IIF technique should be considered as the standard screening method for the detection of ANA [21], the biomedical industry has proposed technological solutions which significantly improve the automation of the procedure, not only in the preparation of substrates and slides, but also in microscope reading. This innovation is based on the principles of digitalization of fluoroscopic images and on the classification of patterns using standardized approaches (automated positive-negative screening and pattern interpretation). These systems are based on the use of automated microscopes, robotized slide trays, high-sensitivity video cameras, and softwares dedicated to acquisition and analysis of digital images [23, 45-47].

Currently, advanced stages of experimentation are taking place on seven commercial systems (Aklides, Medipan, Berlin, Germany; Nova View, Inova, S. Diego, USA; Zenit G Sight, A. Menarini Diagnostics, Florence, Italy;
Europattern, Euroimmun, Luebeck, Germany; Helios, Aesku.Diagnostics, Wendelsheim, Germany; Image Navigator, Immuno Concepts, Sacramento, USA; Cytospot, Autoimmun Diagnostika, Strassberg, Germany). Their characteristics are summarized in Tables 3 and 4.

\section{Types and degree of automation of commercial platforms for indirect immunofluorescence methods}

Aklides

The system consists of a fully motorized inverse microscope (Olympus IX81) with a controllable motorized scanning stage, 400/490 nm light-emitting diodes (LED) and a gray level camera. The interpretation system is controlled by the AKLIDES software. Additional di-amidino2-phenyl-indole (DAPI) stain is used for focusing of objects. Aklides was the first commercially available system. Several recent literature reports show that the system has an excellent diagnostically relevant positive/negative discrimination, with high agreement between automated and visual interpretation: $94.6 \%$ in the study of Hiemann et al. [48] involving 502 samples/subjects; $91-93.0 \%$ in the study of Egerer [49], involving 1,222 patients; 90-95 \% in the study of Kivity [50] concerning 397 samples. In a study of our group [51], the overall agreement was $99.0 \%$ (182 samples). $91 \%$ (44 samples), and $89.1 \%$ (46 samples) for ANA, anti-dsDNA, and ANCA testing, respectively.

\section{Nova View}

The platform consists of the same hardware of the previous system, with different software. At present, there are no published reports about this system. Preliminary data 


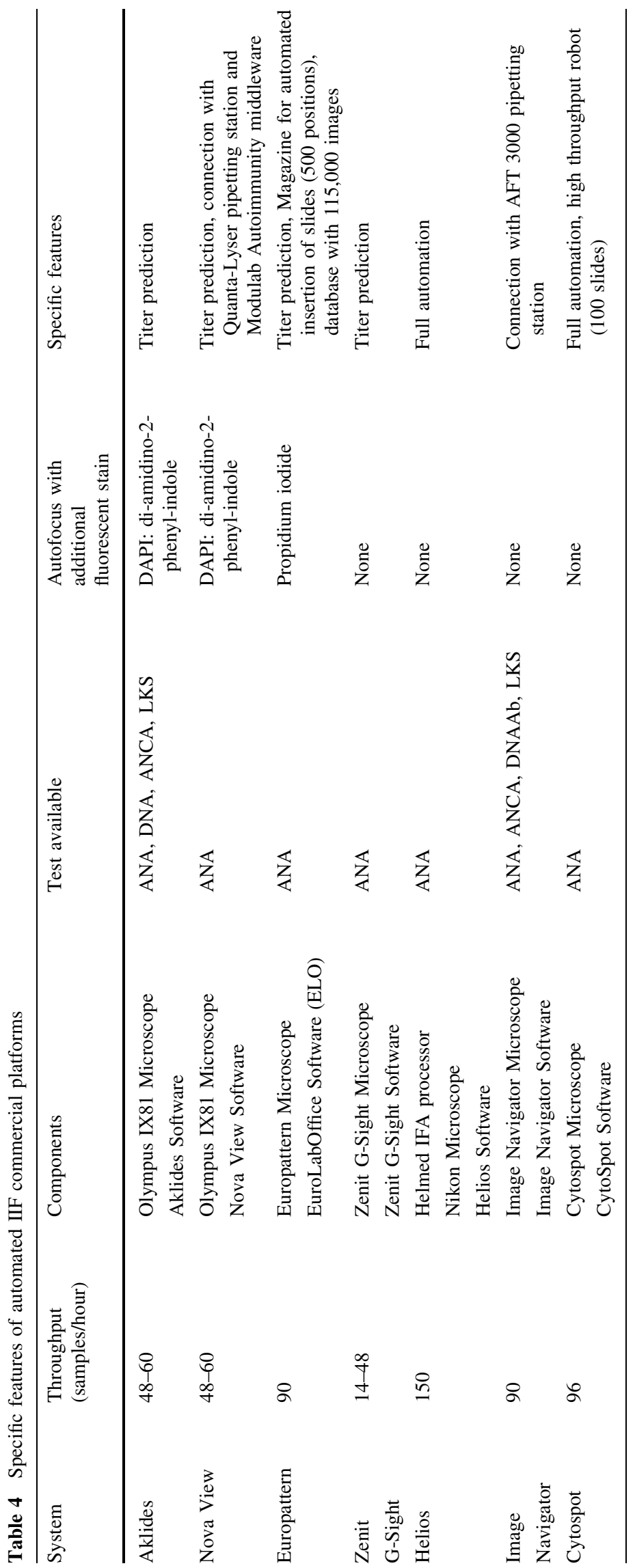


demonstrate that the correlation between the Nova View system and the conventional method ranges from 93-100\%, in the classification of negative-positive samples and in interpretation of fluorescence pattern. In a recent unpublished study by our group, we were able to confirm these data, with agreement between the Nova View System and the manual IIF of $95 \%$.

\section{Europattern}

The instrument consists of a fully motorized microscope that allows the automated processing of up to 500 analysis positions in succession with identification of pattern combinations (including the corresponding titers). The interpretation system is controlled by the EuroLabOffice (ELO) Software, with a reference database containing 115,000 images of samples. In a recent study of our group (unpublished data) aimed to validate this new system, we examined 116 unselected sera from outpatients. The agreement between the automated and manual classification of these sera was $100 \%$ in the case of positive sera and $74 \%$ in the case of negative sera: the overall concordance was $94 \%$.

\section{Zenit G-Sight}

The system consists of a motorized automated fluorescence microscope that allows a semi-quantitative analysis (with different G-Sight indexes) and intelligent pattern recognition for ANA test by the use of a specific software. Published reports are not yet available on the validation of the system. In preliminary studies of different researchers, the system demonstrates a good correlation between the quantitative estimation of ANA intensity and manual ANA titers as assessed by serial dilution and shows a sensitivity of $64 \%$ and a specificity of $97 \%$ at index 24, with a concordance between index-based and validated results of $96 \%$ at index $<14$. In a recent study of our group (preliminary data), we were able to confirm these results, but we found a high percentage of uncertain results.

\section{Helios}

The system was developed based on the IIF processor Helmed. An optical system to capture the respective IIF images was implemented and a specific software algorithm was developed for the differentiation between positive and negative samples; the results can be recorded, saved and transmitted to the laboratory information system and validated remotely. The in-house validation of the system with over 1,000 serum samples showed a $98.4 \%$ correlation of results, when compared to the manual IIF procedure and visual interpretation.
Image Navigator

The system consists of a motorized fluorescence microscope that automates the scanning of patient samples on Immuno Concepts fluorescent HEp-2000 assay by capturing up to four images per field, and sorts them into positive and negative folders for review by the technologist. Unpublished data show a high between-reader agreement (97\%).

\section{Cytospot}

The system consists of fully automated diagnostic microscope for immunofluorescent images that scans all conventional slides and allows a stand-alone differentiation of positive and negative samples and a guided comparison of the output image with images in the library of integrated ANA patterns. For high throughput laboratories, a second version of the system exists (Cytospot Robot) that allows the automated imaging of 100 slides. Currently, the literature reports are not available on the diagnostic accuracy of the system.

\section{Advantages and perspectives of automated IIF cell/tissue assay}

Automation of the IIF method can be used for a costeffective and accurate screening for diagnostically relevant autoantibodies; this technology may play down errors and problems caused by subjective image evaluation and low expertise. The further development of classification algorithms should allow the identification and differentiation of a wide variety of cell and tissue staining patterns.

The expected advantages of an automated IIF method are (a) the reduction in frequency of false negative and false positive results due to the standardization of measurement of fluorescence intensity; (b) the reduction of intra- and inter-laboratory variability; (c) improvement in the correlation of staining patterns with corresponding autoantibody reactivities; and (d) higher throughput in the laboratory workflow.

Conflict of interest None.

\section{References}

1. Tozzoli R, Bonaguri C, Melegari A, Antico A, Bassetti D, Bizzaro N (2012) Current state of diagnostic technologies in the autoimmunology laboratory. Clin Chem Lab Med (in press)

2. Friou GJ (1957) Clinical application of lupus serum-nucleoprotein reaction using fluorescent antibody technique. J Clin Invest 86:890-896 
3. Nairn RC, Ghose T, Porteous IB, Urquhart JA (1962) A routine immunofluorescence method for detecting autoantibodies to thyroid colloid. J Clin Pathol 15:594-595

4. Taylor KB, Roitt IM, Doniach D, Couchman KG, Shapland C (1962) Autoimmune phenomena in pernicious anaemia: gastric antibodies. Brit Med J 2:1347-1352

5. Beutner EH, Jordon RE (1964) Demonstration of skin antibodies in sera of pemphigus vulgaris patients by immunofluorescent staining. Proc Soc Exp Biol Med 117:505-510

6. Walker JG, Doniach D, Roitt IM, Sherlock S (1965) Serological tests in diagnosis of primary biliary cyrrhosis. Lancet 1:827-831

7. Johnson GD, Holborow EJ, Glynn LE (1965) Antibody to smooth muscle in patients with liver disease. Lancet 2:878-879

8. Irvine WJ, Stewart AG, Scarth L (1967) A clinical and immunological study of adrenal insufficiency (Addison's disease). Clin Exp Immunol 2:31-70

9. Anderson JR, Goudie RB, Gray K, Stuart-Smith DA (1968) Immunological features of idiopathic Addison's disease: an antibody to cells producing steroid hormones. Clin Exp Immunol 3:119-131

10. Seah PP, Fry L, Rossiter MA, Hoffbrand AV, Holborow EJ (1971) Anti-reticulin antibodies in childhood celiac disease. Lancet 7726:681-682

11. Rizzetto M, Swana G, Doniach D (1973) Microsomal antibodies in active chronic hepatitis and other disorders. Clin Exp Immunol $15: 331-344$

12. Bottazzo GF, Florin-Christiansen A, Doniach D (1974) Islet-cell antibodies in diabetes mellitus with autoimmune polyendocrine deficiencies. Lancet 7892:1279-1283

13. Bottazzo GF, Pouplard A, Fiorin-Christiansen A, Doniach D (1975) Autoantibodies to prolactin-secreting cells oh human pituitary. Lancet 7925:97-101

14. Unsworth DJ, Leonard JN, McMinn RM, Swain AF, Holborow EJ, Fry L (1981) Anti-gliadin antibodies and small intestinal mucosal damage in dermatitis herpetiformis. Br J Dermatol 105:653-658

15. Chorzelski TP, Beutner EH, Sulej J, Tchorzewska H, Jablonska S, Kumar V et al (1984) IgA anti-endomysium antibody. A new immunological marker of dermatitis herpetiformis and celiac disease. Br J Dermatol 111:395-402

16. Wiik A, Hoier-Madsen M, Forslid J, Charles P, Meyrowitsch J (2010) Antinuclear antibodies: a contemporary nomenclature using HEp-2 cells. J Autoimmun 35:276-290

17. Tozzoli R (2007) Recent advances in diagnostic technologies and their impact in autoimmune diseases. Autoimmun Rev 6:334-340

18. Tozzoli R, Bizzaro N (2012) The clinical autoimmunologost and the laboratory autoimmunologist: the two sides of the coin. Autoimmun Rev (in press)

19. Solomon DH, Kavanaugh AJ, Schur PH (2002) Evidence-based guidelines for the use of immunologic tests: antinuclear antibody testing. Arthritis Rheum 47:434-444

20. Tozzoli R, Bizzaro N, Tonutti E, Villalta D, Bassetti D, Manoni F et al (2002) Guidelines for the laboratory use of autoantibody tests in the diagnosis and monitoring of autoimmune rheumatic diseases. Am J Clin Pathol 117:316-324

21. Meroni PL, Schur PH (2010) ANA screening: an old test with new recommendations. Ann Rheum Dis 69:1420-1422

22. Savige JF, Gillis DF, Benson E, Davies D, Esnault V, Falk RJ et al (1999) International Consensus Statement on testing and reporting of antineutrophil cytoplasmic antibodies (ANCA). Am J Clin Pathol 111:507-513

23. Rigon A, Soda P, Zennaro D, Iannello G, Afeltra A (2007) Indirect immunofluorescence in autoimmune diseases: assessment of digital images for diagnostic purpose. Cytometry B 72B:472-477

24. Fritzler MJ (2011) The antinuclear antibody test: last or lasting gasp? Arthritis Rheum 63:19-22
25. Jaskowski TD, Schroder C, Martins TB, Mouritsen CL, Litwin CM, Hill HR (1996) Screening of antinuclear antibodies by enzyme immunoassay. Am J Clin Pathol 105:468-473

26. Emlen W, O'Neill L (1997) Clinical significance of antinuclear antibodies. Arthritis Rheum 40:1612-1618

27. Gniewek RA, Stites DP, McHugh TM, Hilton JF, Nakagawa M (1997) Comparison of antinuclear antibody testing: immunofluorescence assay versus enzyme immunoassay. Clin Diagn Lab Immunol 4:185-188

28. Homburger HA, Cahen YD, Griffiths J, Jacob GL (1998) Detection of antinuclear antibodies: comparative evaluation of enzyme immunoassay and indirect immunofluorescence methods. Arch Pathol Lab Med 122:993-999

29. Rondeel JM, van Gelder W, van der Leeden H, Dinkelaar RB (1999) Different strategies in the laboratory diagnosis of autoimmune disease: immunofluorescence, enzyme-linked immunosorbent assay or both? Ann Clin Biochem 36:189-195

30. Olaussen E, Rekvig OP (1999) Screening tests for antinuclear antibodies: selective use of central nuclear antigens as a rational basis for screening by ELISA. J Autoimmun 13:95-102

31. Ulvestad E (2001) Performance characteristics and clinical utility of a hybrid ELISA for detection of ANA. APMIS 109:217-222

32. Bernardini S, Infantino M, Bellicampi L, Nuccetelli M, Afeltra A, Lori R et al (2004) Screening of antinuclear antibodies: comparison between enzyme immunoassay based on nuclear homogenates, purified or recombinant antigens and immunofluorescence assay. Clin Chem Lab Med 42:1155-1160

33. Tonutti E, Bassetti D, Piazza A, Visentini D, Poletto M, Bassetto $F$ et al (2004) Diagnostic accuracy of ELISA methods as an alternative screening test to indirect immunofluorescence for the detection of antinuclear antibodies. Evaluation of five commercial kits. Autoimmunity 37:171-176

34. Fenger M, Wiik A, Hoier-Madsen M, Lykkegaard JJ, Rozenfeld T, Hansen MS et al (2004) Detection of antinuclear antibodies by solid-phase immunoassays and immunofluorescence analysis. Clin Chem 50:2141-2147

35. Sinclair D, Saas M, Williams D, Hart M, Goswami R (2007) Can an ELISA replace immunofluorescence for the detection of antinuclear antibodies? The routine use of anti-nuclear antibody screening ELISAs. Clin Lab 53:183-191

36. Lopez-Hoyos M, Rodriguez-Valverde V, Martinez-Taboada V (2007) Performance of antinuclear antibody connective tissue disease screen. Ann NY Acad Sci 1109:322-329

37. Hayashi N, Kawamoto T, Mukai M, Morinobu A, Koshiba M, Kondo $S$ et al (2001) Detection of antinuclear antibodies by use of an enzyme immunoassay with nuclear HEp-2 cell extract and recombinant antigens: comparison with immunofluorescence assay in 307 patients. Clin Chem 47:1649-1659

38. Gonzalez C, Garcia-Berrocal B, Perez J, Navajo JA, Herraez O, González-Buitrago JM (2005) Laboratory screening of connective tissue diseases by a new automated ENA screening assay (EliA Symphony) in clinically defined patients. Clin Chim Acta 359:109-114

39. Ghillani P, Rouquette AM, Desgruelles C, Hauguel N, Le Pendeven C, Piette JC et al (2007) Evaluation of the LIAISON ANA screen assay for antinuclear antibody testing in autoimmune diseases. Ann NY Acad Sci 1109:407-413

40. Op De Beeck K, Vermeesch P, Verscheueren P, Westhovens R, Marien G, Blockmans D et al (2011) Detection of antinuclear antibodies by indirect immunofluorescence and by solid phase assay. Autoimmun Rev 10:801-808

41. Nifli A-P, Notas G, Mamoulaki M, Niniraki M, Ampartzaki V, Theodoropoulos PA et al (2006) Comparison of a multiplex, bead-based fluorescent assay and immunofluorescence methods for the detection of ANA and ANCA autoantibodies in human serum. J Immunol Methods 311:189-197 
42. Bonilla E, Francis L, Allam F, Ogrinc M, Neupane H, Phillips PE et al (2007) Immunofluorescence microscopy is superior to fluorescent beads for detection of antinuclear antibody reactivity in systemic lupus erythematosus patients. Clin Immunol 124: $18-21$

43. Salamunic I, Paukovic-Sekulic B, Galetovic A (2008) Comparative analysis of multiplex AtheNA multi-lyte ANA test system and conventional laboratory methods to detect autoantibodies. Biochemia Medica 18:88-98

44. Hanly JG, Thompson K, McCurdy G, Fougere L, Theriault C, Wilton K (2010) Measurement of autoantibodies using multiplex methodology in patients with systemic lupus erythematosus. J Immunol Methods 352:147-152

45. Hu Y, Murphy RF (2004) Automated interpretation of subcellular patterns from immunofluorescence microscopy. J Immunol Methods 290:93-105

46. Glory EM, Murphy RF (2007) Automated subcellular location determination and high throughput microscopy. Dev Cell $12: 7-16$
47. Rigon A, Buzzulini F, Soda P, Onofri L, Arcarese L, Iannello G et al (2011) Novel opportunities in automated classification of antinuclear antibodies on HEp-2 cells. Autoimmun Rev 10:647652

48. Hiemann R, Buttner T, Krieger T, Roggenbuck D, Sack U, Conrad K (2009) Challenges of automated screening and differentiation of non-organ specific autoantibodies on HEp-2 cells. Autoimmun Rev 9:17-22

49. Egerer K, Roggenbuck D, Hiemann R, Weyer MG, Büttner T, Radau B et al (2010) Automated evaluation of autoantibodies on human epithelial-2 cells as an approach to standardize cell-based immunofluorescence tests. Arthritis Res Ther 12:R40

50. Kivity S, Gilburd B, Agmon-Levin N, Garcia Carrasco M, Tzafrir Y, Sofer Y et al (2012) A novel automated indirect immunofluorescence autoantibody evaluation. Clin Rheumatol 31:503-509

51. Melegari A, Bonaguri C, Russo A, Luisita B, Trenti T, Lippi G (2012) A comparative study on the reliability of an automated system for the evaluation of cell-based indirect immunofluorescence. Autoimmun Rev (Epub ahead of print) 